\title{
Application of Polyaniline Nano Composite for the Adsorption of Acid Dye from Aqueous Solutions
}

\author{
J.RAFFIEA BASERI*1 ${ }^{1}$, P.N.PALANISAMY ${ }^{2}$ and P.SIVAKUMAR ${ }^{3}$ \\ ${ }^{1}$ Department of Chemistry, Al-Ameen Engineering College, Erode, Tamilnadu-638 104, \\ India \\ ${ }^{2}$ Department of Chemistry, Kongu Engineering College, Perundurai, Erode, Tamilnadu- 638 \\ 052 , India \\ ${ }^{3}$ Department of Chemistry, Arignar Anna Government Arts College, Namakkal, Tamilnadu- \\ 637002 , India \\ raffiea2010@gmail.com
}

Received 28 August 2011; Accepted 27 October 2011

\begin{abstract}
In this research, Polyaniline coated sawdust (Polyaniline nano composite) was synthesized via direct chemical polymerization and used as an adsorbent for the removal of acid dye (Acid Violet 49) from aqueous solutions. The effect of some important parameters such as $\mathrm{pH}$, initial concentration of dye, contact time and temperature on the removal efficiency was investigated in batch adsorption system. The adsorption capacity of PAC was high $(96.84$ $\%)$ at a $\mathrm{pH}$ of 3-4. The experimental data fitted well for pseudo second order model. Langmuir model is more appropriate to explain the nature of adsorption with high correlation coefficient. The Energy of activation from arrehenius plot suggested that the adsorption of AV49 onto PAC involves physisorption mechanism.
\end{abstract}

Key words: Sawdust, Langmuir isotherm, polyaniline, arrehenius plot, acid violet 49 .

\section{Introduction}

Among the industries, textile industry plays an important role in the economy of country and it accounts for around one third of total export of India. The wastewater from textile industry causes damages to the ecological system of the receiving surface and affects the ground water resources. Most of the dyes are stable to light and non biodegradable ${ }^{1}$. Therefore dye bath effluents need to be treated before being discharged to the environment ${ }^{2}$.

Among the physico chemical processes, adsorption is considered to be most effective and proven technology for the wastewater treatment. Activated carbon is the most common adsorbent for this process due to its effectiveness and versatility ${ }^{3}$. The regeneration and difficulty of separation from the wastewater after use are major concerns associated with activated carbon. There has been growing interest in finding inexpensive and effective 
alternative to activated carbon such as rice husk $^{4}, \operatorname{chitin}^{5}$, orange waste ${ }^{6}$, lemon peel ${ }^{7}$, raw barley straw ${ }^{8}$, egg shell ${ }^{9}$ and sawdust ${ }^{10}$ etc.

The present study is an attempt to remove the acid dye, AV49 from aqueous solutions by using polyaniline nano composite as an adsorbent. Polyaniline (PA) is a polyaromatic amine that can be easily synthesized chemically on the surface of sawdust from aqueous bronsted acid solutions. Chemical polymerization of aniline in aqueous acidic media can be easily performed using of oxidizing agents such as (NH4)2S2O8.

\section{Experimental}

Adsorbent

Polyaniline Composite was synthesized on sawdust surface of Thevetia peruviana. In order to prepare polymer coated sawdust, $5.0 \mathrm{~g}$ sawdust immersed in $50 \mathrm{~mL}$ of $0.20 \mathrm{M}$ freshly distilled aniline in $1 \mathrm{M} \mathrm{HCl}$ solution for 6 hours before polymerization. The excess of the monomer solution was removed by simple decantation. Then $50 \mathrm{~mL}$ of $0.5 \mathrm{M}\left(\mathrm{NH}_{4}\right)_{2} \mathrm{~S}_{2} \mathrm{O}_{8}$ as an oxidant solution was added into the mixture gradually, and the reaction was allowed to continue for 4 hours at room temperature. The polymer coated sawdust (PAC) was filtered, washed with distilled water, dried in an oven at about $60^{\circ} \mathrm{C}$ and sieved before use ${ }^{11}$. The coating percentage of each polymer onto saw dust determined by weight difference of the dried sawdust before and after coating and it was nearly $5 \%$. The characteristics of the PAC were studied as per the standard procedures ${ }^{12,13}$ and the surface morphology was analyzed by Scanning Electron microscope images.

\section{Adsorbate}

The dye used in this study was Acid Violet 49 having molecular formula $\mathrm{C}_{39} \mathrm{H}_{40} \mathrm{~N}_{3} \mathrm{NaO}_{6} \mathrm{~S}_{2}$ (Mol.Wt:733.87) with CI No. 42640. The molecular structure is given in Figure 1. All the chemicals used were high purity, commercially available analar grade. A stock solution of $1000 \mathrm{mg} / \mathrm{L}$ was prepared by dissolving appropriate amount of dye (based on percentage purity) in one litre of double distilled water. The experimental solutions were obtained by diluting the dye stock solutions in accurate proportions to different initial concentrations.

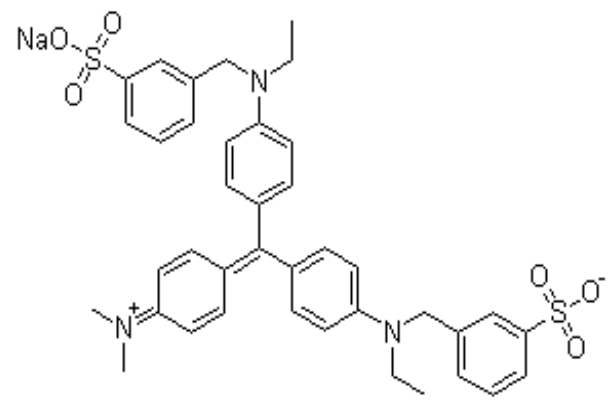

Figure 1 Molecular structure of Acid Violet 49.

\section{Batch mode adsorption experiments}

The adsorption experiments were carried out by agitating $100 \mathrm{mg}$ adsorbent with $200 \mathrm{~mL}$ of dye solutions of 25 to $100 \mathrm{mg} / \mathrm{L}$ concentration at $150 \mathrm{rpm}$ on an Orbital shaker (REMI make). The mixture was withdrawn at specified intervals, centrifuged using electrical centrifuge (Universal make) at 5000rpm for 20 minutes and unadsorbed supernatant liquid was analyzed for the residual dye concentration using Elico make UV Spectrophotometer 
(CI 73) at $548 \mathrm{~nm}$. The effect of $\mathrm{pH}$ was studied by using dilute $\mathrm{HCl}$ and $\mathrm{NaOH}$ solutions. The effect of temperature was studied at four different temperatures $\left(30,35,40\right.$ and $\left.45^{\circ} \mathrm{C}\right)$. All experiments were carried out in duplicate and the mean values are reported, where the maximum deviation was within $4 \%$.

\section{Desorption Studies}

Desorption studies were carried out to analyse the mechanism of adsorption and recovery of the adsorbate and adsorbent. The supernatant was separated after centrifugation and the adsorbent was separated and allowed to agitate with $100 \mathrm{~mL}$ of distilled water at different $\mathrm{pH}(2-11)$ above the equilibrium time of adsorption. The desorbed dye solution was estimated as given in the adsorption studies ${ }^{14}$.

\section{Results and Discussion}

\section{Characterization studies}

The characteristics of PAC are presented in Table 1.

Table 1: Physico - Chemical characteristics of PAC.

\begin{tabular}{|c|c|c|}
\hline S.No & Properties & PAC \\
\hline 1 & $\mathrm{pH}$ & 7.42 \\
\hline 2 & Conductivity, $\mathrm{mS} / \mathrm{cm}^{2}$ & 5.93 \\
\hline 3 & Methylene Blue Number, $\mathrm{mg} / \mathrm{g}$ & 45 \\
\hline 4 & Iodine Number, $\mathrm{mg} / \mathrm{g}$ & 87 \\
\hline 5 & Volatile matter, $\%$ & 56.3 \\
\hline
\end{tabular}

In the SEM micrograph of Sawdust-PPy composite, it can be seen from the figure 2 that the surface of sawdust is coated with PAni nano particles aggregated in clusters having globular particle shape with an average diameter of about $100 \mathrm{~nm}^{15}$.

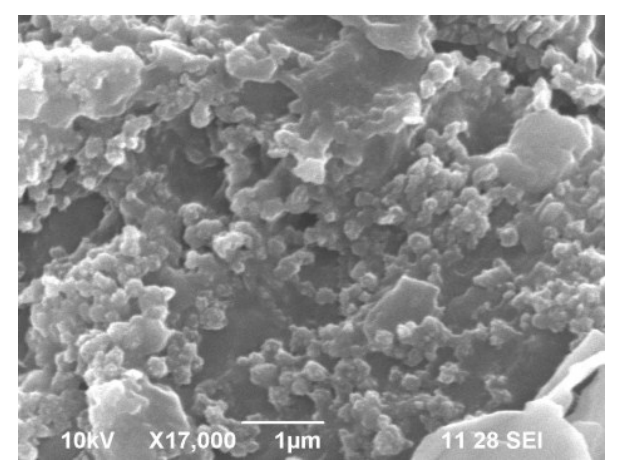

Figure 2 Scanning Electron Microscope of PAC.

\section{Effect of agitation time and initial dye concentration:}

The effect of time on the removal of AV49 by PAC is shown in Figure 3. The percentage of removal increases with time and attains equilibrium at 50 minutes for all concentrations studied ( 25 to $100 \mathrm{mg} / \mathrm{L}$ ). After that no significant change was observed in the extent of adsorption. The amount of dye adsorption increases from $48.42 \mathrm{mg} / \mathrm{g}$ to $173.41 \mathrm{mg} / \mathrm{g}$ while increasing the initial dye concentration from 25 to $100 \mathrm{mg} / \mathrm{L}$. This is due to the fact that with 
increase in dye concentration, the presence of dye molecules near the adsorbent also increased. Similar results were reported for the adsorption of acid dye on activated bleaching earth $^{16}$.

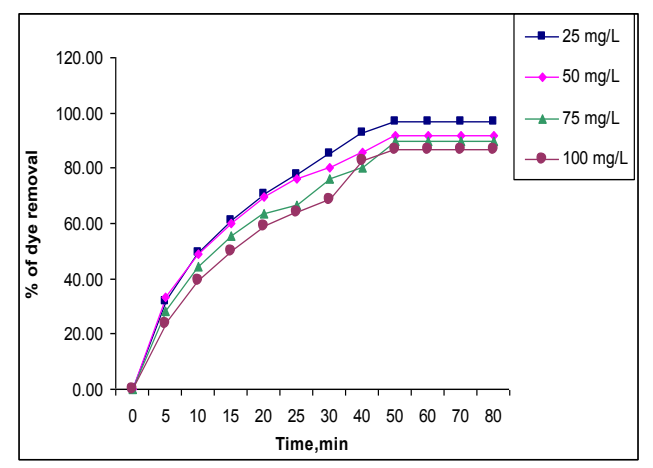

Figure 3 Effect of agitation time on the percentage removal of AV49 dye on PAC at $30^{\circ} \mathrm{C}$ (adsorbent dosage, 100mg; $\mathrm{pH}, 3.4$ ).

\section{Effect of $p H$}

It is found that the percentage removal of AV49 was higher when the $\mathrm{pH}$ is below 5 . After $\mathrm{pH} 5$, the adsorption rate decreased. In acidic conditions, the surface of the adsorbent is positively charged due to high concentration of $\mathrm{H}^{+}$, so electrostatic attraction between the adsorbent and the adsorbate (anionic dye) is enhanced. Lower adsorption of AV49 under alkaline conditions is due to the presence of hydroxyl ions on the surface of adsorbents competing with the adsorbate for adsorption sites ${ }^{17}$.

PAC has positively fixed charged sites which are balanced with the anions $\left(\mathrm{Cl}^{-}\right.$ions) originating from monomer or oxidant solution during their synthesis. The small size dopant anions can be exchanged with other anionic species in treated solutions which have stronger interactions with the polymer ${ }^{18}$. It may be suggested that the rate of anionic dye removal is high due to the ion exchange mechanism between mobile $\mathrm{Cl}^{-}$ions and anionic dye molecules.

\section{Effect of temperature}

It has been observed from Figure 4 that the percentage removal of AV49 by PAC increases from $91.96 \%$ to $97.32 \%$ on increasing the temperature from $30^{\circ} \mathrm{C}$ to $45^{\circ} \mathrm{C}$. This indicates that the sorption of anionic dyes is endothermic in nature ${ }^{19}$. These adsorption data were further analyzed with adsorption isotherm models to find out the suitable model.

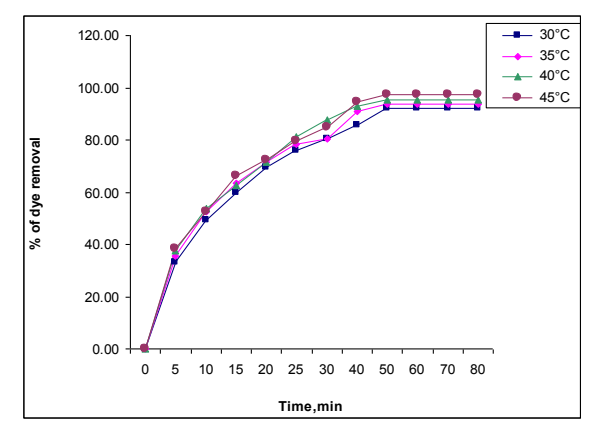

Figure 4 Effect of temperature on the adsorption of AV 49 dye on to PAC at initial concentration of $50 \mathrm{mg} / \mathrm{L}$ (adsorbent dosage, 100mg; $\mathrm{pH}, 3.4$ ). 


\section{Equilibrium adsorption isotherm}

The Langmuir adsorption isotherm has been used successfully for many adsorption processes of monolayer adsorption. Langmuir model ${ }^{20}$ is represented by the following equation

$$
\frac{C_{e}}{q_{e}}=\frac{1}{Q_{o} b_{L}}+\left(\frac{1}{Q_{o}}\right) C_{e}
$$

where, $\mathrm{q}_{\mathrm{e}}$ is the amount of dye adsorbed at equilibrium $(\mathrm{mg} / \mathrm{g}), \mathrm{Q}_{0}$ is the monolayer adsorption capacity $(\mathrm{mg} / \mathrm{g})$ and $\mathrm{b}_{\mathrm{L}}$ is Langmuir constant related to energy of adsorption, $\mathrm{C}_{\mathrm{e}}$ is the equilibrium concentration $(\mathrm{mg} / \mathrm{L})$.

Figure 5 shows a linear plot of $\mathrm{C}_{\mathrm{e}} / \mathrm{q}_{\mathrm{e}}$ against $\mathrm{C}_{\mathrm{e}}$ for the removal of AV49 by PAC. The Langmuir adsorption capacity varies from $188.67 \mathrm{mg} / \mathrm{g}$ to $204.08 \mathrm{mg} / \mathrm{g}$ for AV49 onto PAC with increase in temperature from $30^{\circ} \mathrm{C}$ to $45^{\circ} \mathrm{C}$. This indicates that the adsorption is favored at high operating temperature. Similar results were reported for the removal of basic and acidic dyes by the low cost adsorbent ${ }^{21}$. The Langmuir isotherm fits quite well with the experimental data with good correlation coefficient as shown in Table 2.

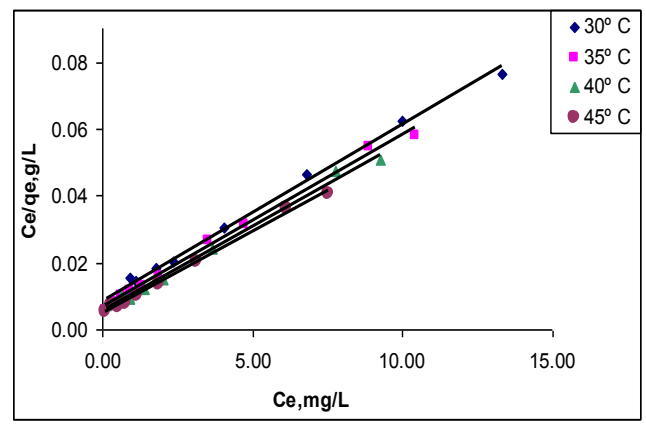

Figure 5 - Langmuir adsorption isotherm plot for the adsorption of AV49 dye onto PAC (adsorbent dosage, 100mg; $\mathrm{pH}, 3.4$; agitation time, $100 \mathrm{~min}$ ).

The separation factor $\mathrm{R}_{\mathrm{L}}$ is calculated by the following equation to confirm the favorability of the adsorption process ${ }^{22}$. The values of $\mathrm{R}_{\mathrm{L}}$ found to be between 0 and 1 and confirm that the adsorption process is favorable.

$$
\mathrm{R}_{\mathrm{L}}=1 /\left(1+\mathrm{b}_{\mathrm{L}} \cdot \mathrm{C}_{0}\right)
$$

The Freundlich isotherm is an empirical relationship describing the sorption of solutes from a liquid to a solid surface. Freundlich ${ }^{23}$ model is expressed as

$$
\log q_{e}=\log k_{f}+\frac{1}{n} \log C_{e}
$$

A plot of $\log \mathrm{q}_{\mathrm{e}}$ versus $\log \mathrm{C}_{\mathrm{e}}$ gives a linear line with a slope of $1 / \mathrm{n}$ and intercept of $\log \mathrm{k}_{\mathrm{f}}$ and the results are given in Table 2 . From the experimental data, $\mathrm{k}_{\mathrm{f}}$ values increased with increasing temperature for AV 49, implying that the adsorption process may be endothermic in nature. Values $\mathrm{n}>1$ represent a favorable adsorption condition. The correlation coefficient values are poor compared to the Langmuir isotherm model.

The D-R isotherm describes the adsorption on a single uniform pore. DubininRaduskevich isotherm ${ }^{24}$ is generally expressed as follows

$$
q_{e}=q_{D} \cdot e^{-B \varepsilon^{2}}
$$


Table 2: Isotherm Constants for the adsorption of AV49 dye onto PAC at various Temperatures.

\begin{tabular}{|c|c|c|c|c|c|c|c|c|c|}
\hline \multirow{2}{*}{$\begin{array}{c}\text { Temperature } \\
\left({ }^{\circ} \mathrm{C}\right)\end{array}$} & \multicolumn{3}{|c|}{ Langmuir Isotherm } & \multicolumn{3}{c|}{ Freundlich Isotherm } & \multicolumn{3}{c|}{ D-R Isotherm } \\
\cline { 2 - 10 } & $\begin{array}{c}\mathrm{Q}_{0} \\
\mathrm{mg} / \mathrm{g})\end{array}$ & $\begin{array}{c}\mathrm{b}_{\mathrm{L}} \\
(\mathrm{L} / \mathrm{mg})\end{array}$ & $\mathrm{r}^{2}$ & $\mathrm{n}$ & $\begin{array}{c}\mathrm{k}_{\mathrm{f}} \\
\left(\mathrm{mg}^{1-1 / \mathrm{n}}\right. \\
\left.\mathrm{L}^{1 / \mathrm{n}} \mathrm{g}^{-1}\right)\end{array}$ & $\mathrm{r}^{2}$ & $\begin{array}{c}\mathrm{q}_{\mathrm{D}} \\
(\mathrm{mg} / \mathrm{g})\end{array}$ & $\begin{array}{c}\mathrm{E} \\
(\mathrm{kJ} / \mathrm{mol})\end{array}$ & $\mathrm{r}^{2}$ \\
\hline 30 & 188.68 & 0.6235 & 0.9954 & 2.16 & 62.9071 & $\begin{array}{c}0.948 \\
5\end{array}$ & 121.89 & 2.6720 & 0.8765 \\
\hline 35 & 192.31 & 0.7647 & 0.9954 & 2.11 & 70.3558 & $\begin{array}{c}0.943 \\
5\end{array}$ & 126.67 & 2.8860 & 0.9418 \\
\hline 40 & 200.00 & 0.8621 & 0.9943 & 2.01 & 76.6832 & $\begin{array}{c}0.886 \\
9\end{array}$ & 137.32 & 2.6720 & 0.9373 \\
\hline 45 & 204.08 & 1.0208 & 0.9954 & 2.01 & 85.6446 & $\begin{array}{c}0.896 \\
9\end{array}$ & 141.26 & 2.8860 & 0.9030 \\
\hline
\end{tabular}

The linear form of $\mathrm{D}-\mathrm{R}$ isotherm equation is represented as:

$$
\begin{aligned}
& \ln q_{e}=\ln q_{D}-B \varepsilon^{2} \\
& \varepsilon=R T \ln \left(1+\frac{1}{C_{e}}\right)
\end{aligned}
$$

Where $\mathrm{q}_{\mathrm{D}}$ is the theoretical saturation capacity ( $\left.\mathrm{mol} / \mathrm{g}\right), \mathrm{B}$ is a constant related to the mean free energy of adsorption per mole of the adsorbate $\left(\mathrm{mol}^{2} / \mathrm{J}^{2}\right), \varepsilon$ is the Polanyi potential, $\mathrm{R}$ $(\mathrm{J} / \mathrm{mol} / \mathrm{K})$ is the gas constant and $\mathrm{T}(\mathrm{K})$ is the absolute temperature. The D-R constants $\mathrm{q}_{\mathrm{D}}$ and $\mathrm{B}$ were calculated from the linear plots of $\ln \mathrm{q}_{\mathrm{e}}$ versus $\varepsilon^{2}$ (figure not shown) are given in Table 2. The constant $B$ gives an idea about the mean free energy $E(\mathrm{~kJ} / \mathrm{mol})$ of adsorption per molecule of the adsorbate when it is transferred to the surface of the solid from infinity in the solution and can be calculated from the following relationship ${ }^{25}$

$$
\mathrm{E}=1 /(2 \mathrm{~B})^{1 / 2}
$$

The adsorption is physisorption if the energy of activation is in the range of $5-40 \mathrm{~kJ} /$ mol and chemisorption if the energy of activation is between $40-800 \mathrm{~kJ} / \mathrm{mol}$. The results from Table 2 suggest that the adsorption of AV 49 by PAC is physisorption in nature. D-R isotherm is not able to describe the experimental data properly because of the poor linear correlation coefficient for the adsorption of the dye onto PAC at different temperatures.

\section{Kinetics of Adsorption}

Adsorption kinetics is necessary for the design of adsorption systems ${ }^{26}$. In this present study, the following two kinetic models were applied for the experimental data.

Pseudo first - order kinetic model assumes that the rate of change of solute uptake with time is directly proportional to difference in saturation concentration and the amount of solid uptake with time ${ }^{27}$. The rate constant of adsorption is expressed as a first - order rate expression given as:

$$
\log \left(q_{e}-q_{t}\right)=\log q_{e}-\frac{k_{1}}{2.303} t
$$

Where, $\mathrm{k}_{1}$ is the pseudo-first-order rate constant $\left(\mathrm{min}^{-1}\right)$.

The plot of $\log \left(\mathrm{q}_{\mathrm{e}}-\mathrm{q}_{\mathrm{t}}\right)$ versus $\mathrm{t}$ should give a straight line with slope of $-\mathrm{k}_{1} / 2.303$ and intercept $\log \mathrm{q}_{\mathrm{e}}$ which allows calculation of adsorption rate constant $\mathrm{k}_{1}$ and equilibrium adsorption capacity $\mathrm{q}_{\mathrm{e}}$. Calculated values of $\mathrm{k}_{1}$ and $\mathrm{q}_{\mathrm{e}}$ for the adsorption of AV49 dye on 
PAC are summarized in Table 3. The pseudo first-order kinetic model of Lagergren does not fit well with the experimental data over the whole range of initial concentrations studied.

Table 3: Kinetic parameters for the adsorption of AV 49 onto PAC.

\begin{tabular}{|l|c|c|c|c|c|c|c|c|}
\hline \multirow{2}{*}{ Parameter } & \multicolumn{9}{c|}{ Initial dye concentration, $\mathrm{mg} / \mathrm{L}$} & \multicolumn{7}{c|}{ Temperature, ${ }^{\circ} \mathrm{C}$} \\
\cline { 2 - 9 } & 25 & 50 & 75 & 100 & 30 & 40 & 45 & 50 \\
\hline $\mathrm{q}_{\mathrm{e}}$ exp. $(\mathrm{mg} / \mathrm{g})$ & 48.42 & 91.96 & 134.59 & 173.41 & 91.96 & 93.75 & 95.54 & 97.32 \\
\hline \multicolumn{8}{|c|}{ Pseudo first order kinetics } \\
\hline $\mathrm{k}_{1 \times} 10^{-2}\left(\mathrm{~min}^{-1}\right)$ & 5.48 & 6.43 & 7.19 & 7.76 & 6.43 & 6.47 & 6.49 & 6.56 \\
\hline $\mathrm{q}_{\mathrm{e}} \mathrm{cal}(\mathrm{mg} / \mathrm{g})$ & 35.89 & 76.31 & 142.96 & 203.66 & 76.31 & 72.18 & 70.42 & 76.77 \\
\hline $\mathrm{r}^{2}$ & 0.9155 & 0.9337 & 0.9183 & 0.9202 & 0.9337 & 0.9194 & 0.9186 & 0.9191 \\
\hline \multicolumn{8}{|c|}{ Pseudo second order kinetics } \\
\hline $\mathrm{k}_{2} \times 10^{-4}(\mathrm{~g} / \mathrm{mg} \min )$ & 14.45 & 8.85 & 4.50 & 2.74 & 8.85 & 9.65 & 9.66 & 8.97 \\
\hline $\mathrm{h}$ & 4.7733 & 10.0200 & 11.6959 & 12.9702 & 10.0200 & 11.1607 & 11.6686 & 11.3250 \\
\hline $\mathrm{q}_{\mathrm{e}} \mathrm{cal}(\mathrm{mg} / \mathrm{g})$ & 57.47 & 106.38 & 161.29 & 217.39 & 106.38 & 107.53 & 109.89 & 112.36 \\
\hline $\mathrm{r}^{2}$ & 0.9953 & 0.9973 & 0.9957 & 0.9916 & 0.9973 & 0.9971 & 0.9960 & 0.9966 \\
\hline
\end{tabular}

The pseudo second-order kinetic equation is expressed as ${ }^{28}$

$$
\frac{t}{q_{t}}=\frac{1}{k_{2} q_{e}^{2}}+\frac{t}{q_{e}}
$$

where, $k_{2}$ is the rate constant of pseudo second -order adsorption ( $\mathrm{g} / \mathrm{mg} \min$ ) and $q_{e}$ is the equilibrium adsorption capacity $(\mathrm{mg} / \mathrm{g})$.

Fig 6 shows the pseudo second -order plot for the adsorption of AV49 dye by PAC at various initial dye concentrations (Temperature $30^{\circ} \mathrm{C}$ ). A plot of $t / \mathrm{q}_{\mathrm{t}}$ against $\mathrm{t}$ should give a linear relationship from which $k_{2}$ and $\mathrm{q}_{\mathrm{e}}$ can be determined from the intercept and slope of the plot. The correlation coefficient values are greater than 0.99 (Table 3) and the data points give a linear straight line. It indicates that the adsorption of AV49 dye by PAC follow the pseudo second order kinetic model.

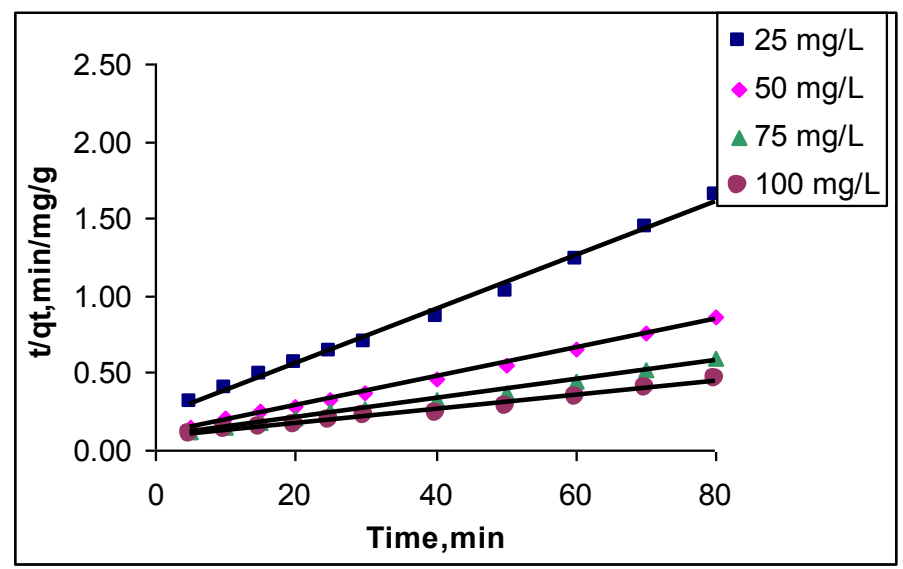

Figure 6 Pseudo second order plot for the adsorption of AV 49 onto PAC at $30^{\circ} \mathrm{C}$

(adsorbent dosage, 100mg; pH, 3.4). 


\section{Thermodynamics analyses}

Langmuir isotherm equation was applied to calculate the thermodynamic parameters as follows:

$$
\begin{array}{r}
\Delta G^{\circ}=-R T \ln k_{L} \\
\ln \mathrm{k}_{L}=\frac{\Delta S^{\circ}}{R}-\frac{\Delta H^{\circ}}{R} \frac{1}{T}
\end{array}
$$

where $\mathrm{k}_{\mathrm{L}}$ is the Langmuir equilibrium constant, $\Delta H^{\circ}$ and $\Delta S^{\circ}$ is the standard enthalpy and entropy changes of adsorption respectively.

Thermodynamic parameters like $\Delta H^{\circ}, \Delta S^{\circ}$ and $\Delta G^{\circ}$ were determined from the slope and intercept of Van't Hoff's plot of $\ln \mathrm{k}_{\mathrm{L}}$ versus $1 / \mathrm{T}$ (figure not shown). Table 4 shows the thermodynamic results for the removal of AV49 by PAC. The decrease in the negative values of $\Delta G^{\circ}$ with an increase in temperature $\left(30\right.$ to $45^{\circ} \mathrm{C}$ ) indicates that the adsorption becomes more favorable at high temperature. The positive $\Delta H^{\circ}$ values indicate that the adsorption of AV49 dye onto PAC is endothermic process. Furthermore the positive $\Delta S^{\circ}$ indicates that the degrees of freedom increased at the solid - liquid interface during adsorption of acid dye onto PAC. Generally, $\Delta G^{\circ}$ for physisorption is between -20 to 0 $\mathrm{kJ} / \mathrm{mol}$ and for chemisorption is between -80 to $-400 \mathrm{~kJ} / \mathrm{mol}^{29}$. The $\Delta G^{\circ}$ Values from Table 4 confirm that the adsorption of AV49 by PAC is physisorption in nature.

\begin{tabular}{|c|c|c|c|}
\hline Temperature, ${ }^{\circ} \mathrm{C}$ & $\Delta \mathbf{H}^{\mathbf{o}}, \mathrm{kJ} / \mathrm{mol}$ & $\Delta S^{o}, \mathrm{~kJ} / \mathrm{K} / \mathrm{mol}$ & $\Delta \mathbf{G}^{\mathbf{0}}, \mathbf{k J} / \mathbf{m o l}$ \\
\hline 30 & \multirow{4}{*}{30.0285} & \multirow{4}{*}{0.1388} & -12.0279 \\
\hline 35 & & & -12.7219 \\
\hline 40 & & & -13.4159 \\
\hline 45 & & & -14.1099 \\
\hline
\end{tabular}

Table 4 : Thermo dynamical parameters for the adsorption of AV 49 onto PAC.

The pseudo second order rate constant $\mathrm{K}_{2}$ of the dye adsorption is expressed as a function of temperature by Arrhenius relationship using the Equation

$$
\ln \mathrm{k}_{2}=\ln A-\frac{E_{a}}{R T}
$$

The value of $E_{a}$ is calculated as $2.225 \mathrm{~kJ} / \mathrm{mol}$ from the slope of a plot of $\ln \mathrm{k}_{2}$ versus $1 / \mathrm{T}$ (Figure not shown). This confirmed that physisorption is predominantly operating force along with very weak chemical forces of attraction.

\section{Desorption studies}

Maximum desorption of $80.2 \%$ for AV49 dye was observed at a pH range of 8 to 9 . Desorption of Anionic dyes from PAC using alkaline solution may imply that physisorption mechanism of the anionic dye molecules along with weak chemical forces of attraction onto PAC. 


\section{Conclusions}

In this investigation, Polyaniline nano composite was easily synthesized by chemical oxidation method directly on the surface of sawdust of Thevetia Peruviana. Removal of AV49 is $\mathrm{pH}$ dependent and the maximum removal was attained at $\mathrm{pH} 3-4$. The adsorption of the dyes increased with increase in temperature from $30^{\circ} \mathrm{C}$ to $45^{\circ} \mathrm{C}$ indicates that the adsorption is endothermic in nature, which was well supported by positive $\Delta \mathrm{H}^{\circ}$ values. Kinetic studies showed that adsorption of AV49 followed pseudo-second order model. The data obtained from adsorption isotherms are well fitted with Langmuir model which suggests the monolayer coverage of the dyes on surfaces of PAC. The Langmuir adsorption capacity varies from $188.67 \mathrm{mg} / \mathrm{g}$ to $204.08 \mathrm{mg} / \mathrm{g}$ for AV49 onto PAC with increase in temperature from $30^{\circ} \mathrm{C}$ to $45^{\circ} \mathrm{C}$. The negative $\Delta G^{\circ}$ values obtained from Van't Hoff plots confirmed that the adsorption of AV49 is spontaneous in nature. It was suggested that PAC can be used as a potential adsorbent for the removal of acidic dyes from aqueous solutions.

\section{References}

1. Joshi K M and Srivastava V S, Int J Chem Tech Research, 2010, 2(1), 427 - 435.

2. Vera G, Aleksandra V and Marana S, Dyes and Pigments, 2005, 67, 93 - 97.

3. Bayramoglu G and Arica M Y, J Hazard Mater, 2007, 143, 135 - 143.

4. Kumar U and Bandyopadhyay M, Biores. Technol., 2006, 97(1), 104 - 109.

5. Ghimire K N, Inove K, Niyajima T, Yashizuka K and Shoji T, Chitin and Chitosan research, 2001, 7(2), $61-68$.

6. Dhakal R P, Ghimire K N, Inove K, Yano M and Makino K, Sep.Purif.Technol., 2005, 42(3), $219-225$.

7. Kumar K V, Dyes and Pigments, 2007, 74(3), 595 -597.

8. Husseien M, Amer A A, El-Maghraby A and Taha N A, J Applied Science Res., 2007, 3(11), $1352-1358$.

9. Pramanpol N and Nitayapat N, The kasetsart Journal, 2006, 40, 192 - 197.

10. Jadhav D N and Vanjara A K, Ind J Chem Tech., 2004,11, 42 - 50.

11. Reza Ansari, Zahra Mosayebzadeh, Mohammed Banimahd keivani and Ali

Mohammed - khah, J.Adv.Sci.Res, 2011, 2(2), 27-34.

12. ISI, Activated Carbon, Bureau of Indian Standards, New Delhi, 1989, IS 877.

13. American Society for Testing Materials (ASTM), 1980, D4607-94.

14. Ahsan Habib, Zahidul Hasan, Shajedu Rahman A S M and Shafiqul Aslam A M, Pakistan J Analytical Environ Chem., 2006, 7, 112- 115.

15. Mazyar Sharifzadeh Baei, Vahid Babaee and Faeqeh Pirouz, 2nd International Conference on Chemistry and Chemical Engineering, 2011, IPCBEE 14, Singapore.

16. Tsai W T, Chang C Y, Ing C H and Chang C F, J Colloid Interface Sci.,2004 ,275, 72 -78.

17. Vinod Kumar Konaganti, Ramanjaneyulu Kota, Sathish Patil and Giridhar Madras, Chem Eng J.,2010, 158, 393 - 401.

18. Reza Ansari and Zahra Mosayebzadeh, Iranian polymer journal, 2010, 19(7), 541 - 551.

19. Jaikumar V, Sathish Kumar K and Gnana Prakash D, Int J App Sci Eng.,2009, 7(2), 115 125.

20. Langmuir I, J Am Chem Soc., 1916, 38(11), 2221 - 2295.

21. Arivoli S, Sundaravadivelu M and Ilango K P, Ind J Chem Tech, 2008, 15, 130 - 139.

22. Filipkowska U, Klimiuk E, Grabowski S and Siedlecka E, Polish J Environ Studies, 2002, 11(4), $315-323$.

23. Freundlich H M F, J Phy Chem., 1906, 57A, 385-470. 
24. Subha R, Namasivayam C, Ind J Chem Tech, 2009, 16, 471 - 479.

25. Chao- Yin Kuo, Chung - Hsin Wu and Jane-Yii Wu, J Colloid Interface Sci., 2008,327, $308-315$.

26. Atef Alzaydien S and Waleed Manasreh, Int J Phy Sci., 2009, 4(4), 172 - 181.

27. Lagergran S, Kung Sven Veten Hand., 1898, 24, 1 -39.

28. Ho Y S, Mckay G, Water Res., 2000, 34, 735 - 742.

29. Jaycock M J and Parfitt C D (1981), Ellis Horwood Ltd., Chichester. 


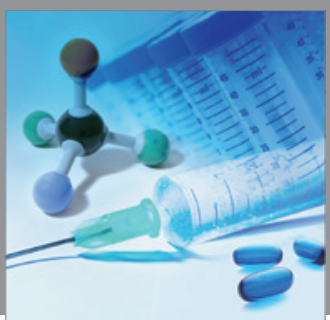

International Journal of

Medicinal Chemistry

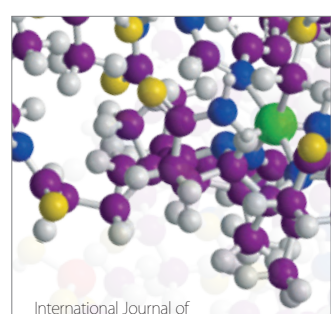

Carbohydrate Chemistry

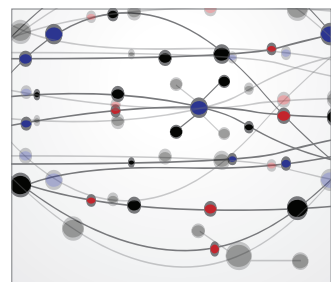

The Scientific World Journal
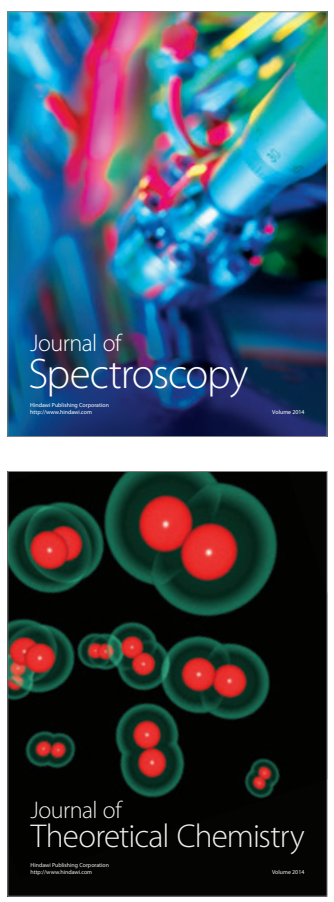
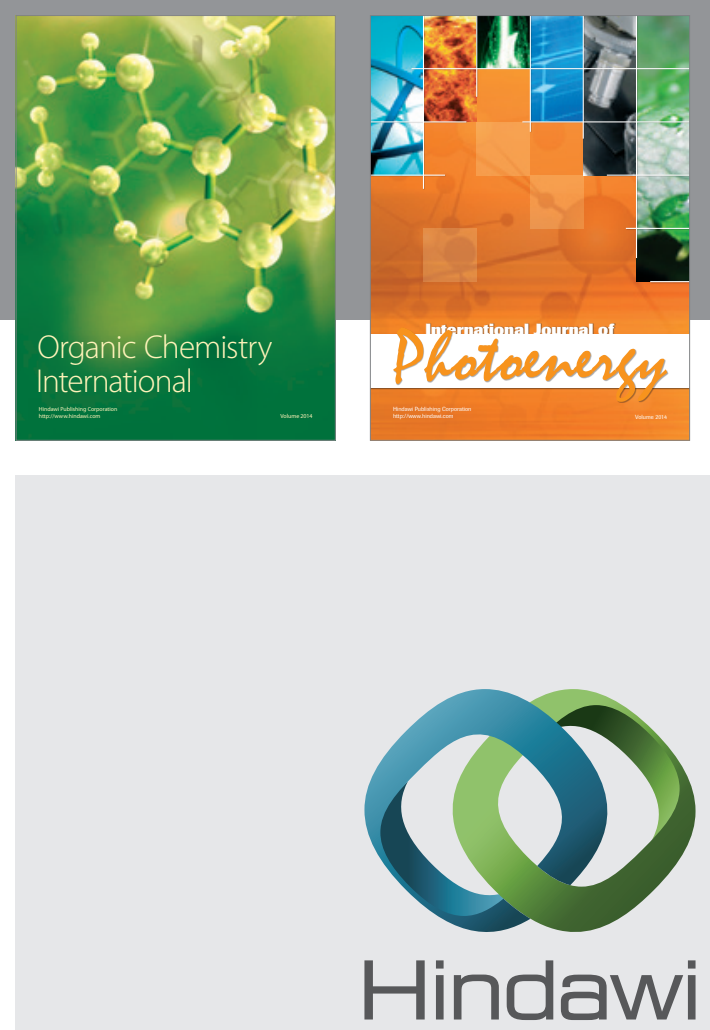

Submit your manuscripts at

http://www.hindawi.com
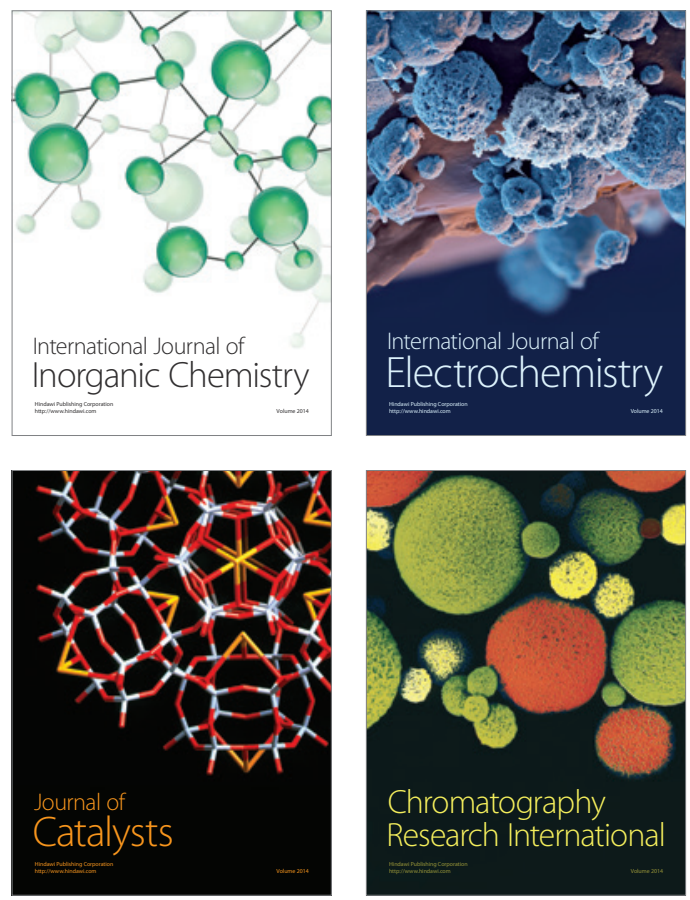
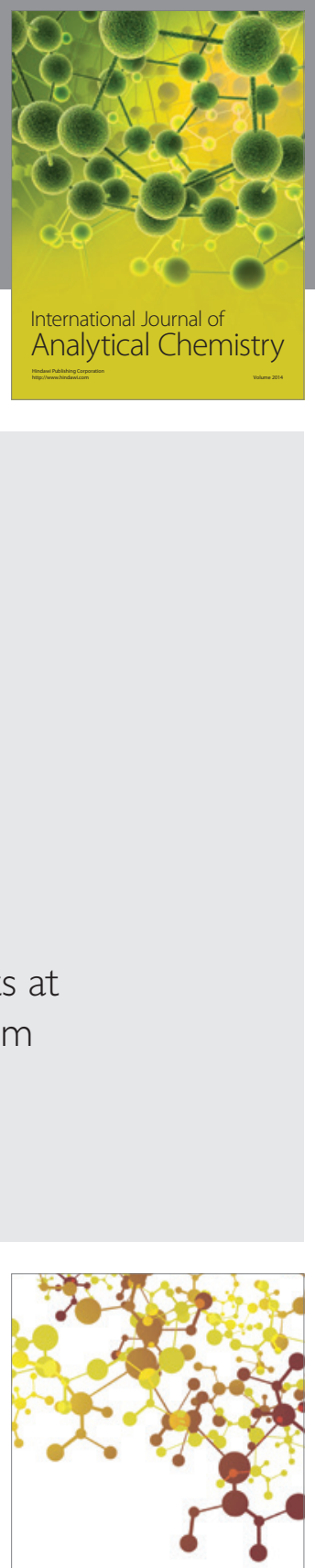

Journal of

Applied Chemistry
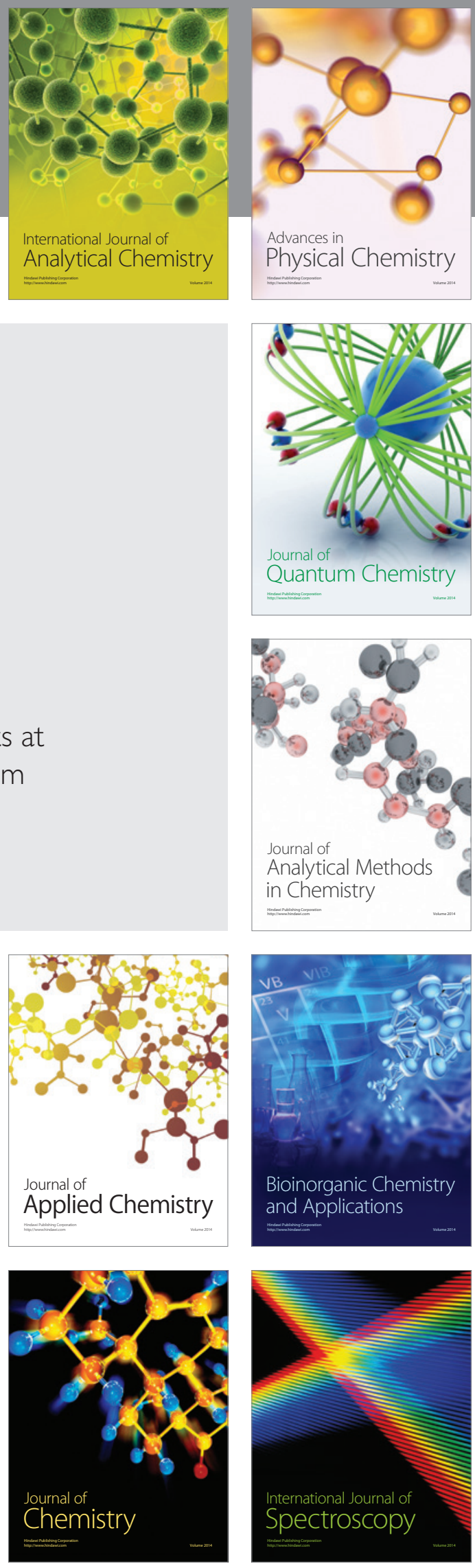